\title{
Drug-related problems: evaluation of a classification system in the daily practice of a Swiss University Hospital
}

\author{
Markus L. Lampert · Stephan Kraehenbuehl • \\ Balthasar L. Hug
}

Received: 7 August 2007/Accepted: 10 March 2008/Published online: 21 March 2008

(C) Springer Science+Business Media B.V. 2008

\begin{abstract}
Aim To evaluate the Pharmaceutical Care Network Europe (PCNE) classification system as a tool for documenting the impact of a hospital clinical pharmacology service. Setting Two medical wards comprising totally 85 beds in a university hospital. Main outcome measure Number of events classified with the PCNE-system, their acceptance by the medical staff and cost implications. Methods Clinical pharmacy review of pharmacotherapy on ward rounds and from case notes were documented, and identified drug-related problems (DRPs) were classified using the PCNE system version 5.00. Results During 70 observation days 216 interventions were registered of which 213 (98.6\%) could be classified: $128(60.1 \%)$ were detected by reviewing the case notes, $33(15.5 \%)$ on ward rounds, $32(15.0 \%)$ by direct reporting to the clinical pharmacist (CP), and $20(9.4 \%)$ on non-formulary prescriptions. Of 148 suggested interventions by the CP 123 $(83.0 \%)$ were approved by the responsible physician, 12 ADR reports $(8.1 \%)$ were submitted to the local pharmacovigilance centre and $31(20.9 \%)$ specific information given without further need for action. An evaluation of the DRPs showed that direct drug costs of $€ 2,058$ within the study period or $€ 10,731$ per year could be avoided.
\end{abstract}

M. L. Lampert

Department of Pharmaceutical Sciences,

Institute of Clinical Pharmacy, University of Basel,

Basel, Switzerland

S. Kraehenbuehl

Clinical Pharmacology \& Toxicology,

University Hospital Basel, Basel, Switzerland

B. L. Hug ( $ه)$

Department of Internal Medicine, University Hospital Basel, 4031 Basel, Switzerland

e-mail: bhug@uhbs.ch
Conclusion We consider the PCNE system to be a practical tool in the hospital setting, which demonstrates the values of a clinical pharmacy service in terms of identifying and reducing DRPs and also has the potential to reduce prescribing costs.

Keywords Adverse drug events .

Adverse drug reactions - Classification systems .

Clinical pharmacist - Cost · Drug-related problems .

Hospital care - PCNE DRP classification .

Pharmaceutical interventions · Switzerland

\section{Impact of findings on practice}

- The PCNE-classification system is suitable for daily hospital practice and a useful tool for documenting clinical pharmacy activities.

- Structured documentation with the PCNE-classification allows performance measurement of clinical pharmacy services.

\section{Introduction}

Drug-related problems are a major safety issue for hospitalized patients. A review of the literature from 1990 to 2005 found that on average $8 \%$ of hospitalised patients experience an adverse drug event (ADE), and $5-10 \%$ of all drug prescriptions or drug applications are erroneous [1]. In general internal medicine $14.6 \%$ of hospitalized patients and approximately $12 \%$ to $17 \%$ of patients after discharge experience ADEs [2, 3]. Interventions by clinical pharmacists have been shown to be effective in reducing DRPs with positive outcomes on the number of ADEs, medication 
appropriateness and resource use. A systematic literature review of controlled studies evaluating the effects of interventions by clinical pharmacists on hospitalized adults found that ADEs, adverse drug reactions (ADR) and MEs were reduced in 7 of 12 trials that included these outcomes [4]. Medication adherence, knowledge, and appropriateness of drug use improved in 7 of 11 studies and the length of hospital stay was shortened in 9 of 17 trials.

From an economic point of view clinical pharmacy services are also favourable. A summary of literature from 1996 to 2000 found 16 studies reporting a cost-benefit ratio ranging from 1.7:1 to 17:1 with a median of 4.68:1 [5].

In many of these studies, however, definitions of detected or prevented problems such as ADRs, ADEs, medication errors or prescribing errors are not consistent. This may cause difficulties in documentation and classification of pharmaceutical interventions and may impair the comparability of the studies. A comprehensive overview of used definitions has been published recently [6].

Due to the inconsistency of definition we have used the more general term of DRPs in this publication. A drugrelated problem (DRP) can be defined as an event or circumstance involving drug therapy that actually or potentially interferes with desired health outcomes [7]. It represents ineffective and unsafe drug use, which may cause or constitute risk factors for MEs, ADEs, ADRs [8].

After having introduced a clinical pharmacy service on two wards we documented the effect of a clinical pharmacist's interventions on DRPs. The main objective was to evaluate the practicality of use of the classification system under daily conditions and to explore its usefulness to derive performance indicators of the clinical pharmacy service.

\section{Methods}

\section{Classification system}

Several classification systems have been proposed in the literature, with only some of them being validated [9-11]. We chose the PCNE classification system for drug-related problems (version 5.00) [7], since it contains most of the required aspects described in a late review of classification systems [12]. To our knowledge the system has been used in primary care but not in hospital settings. To support continuity of care one single system for the documentation of clinical pharmacy activities is desirable. The PCNE system attributes four items to each observation-(1) coding for the problem itself, (2) the actual or suspected cause of the problem, (3) the intervention required to resolve the DRP, and (4) its outcome. An example to illustrate this code is given in Fig. 1.

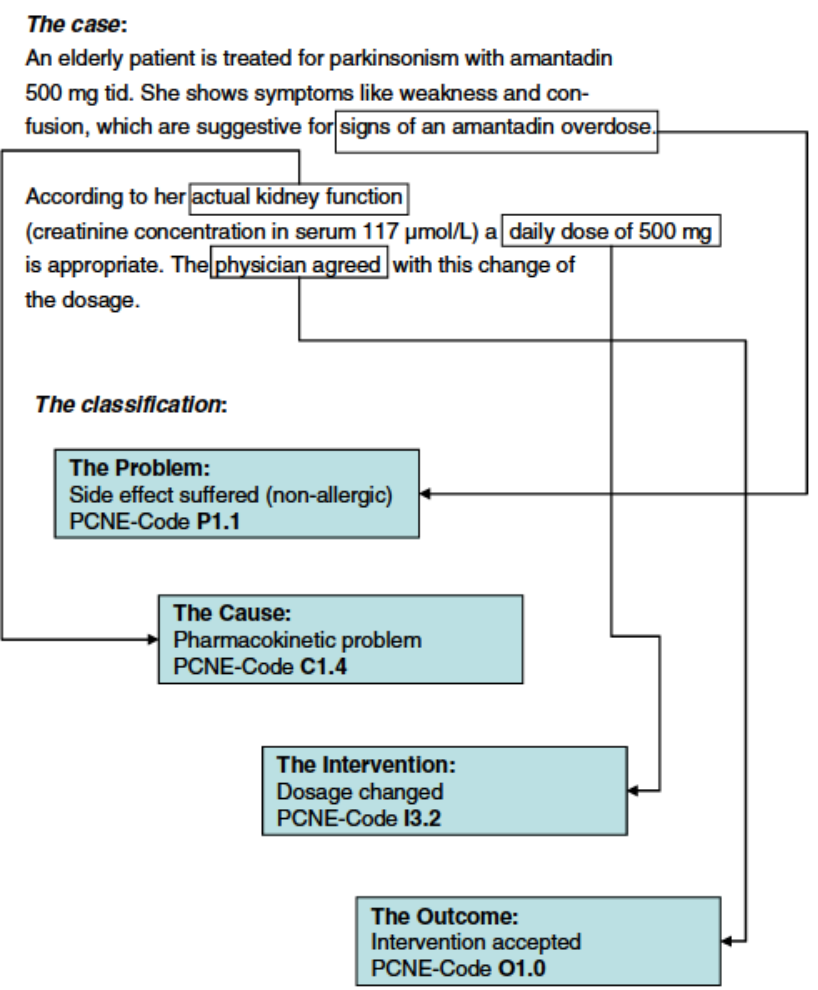

Fig. 1 Example of a pharmaceutical intervention classified as a drug related problem according to PCNE Classification System V5.00

Study design and setting

We conducted a prospective, observational study of clinical pharmacy interventions in a tertiary 700-bed university hospital setting. The two observed wards ( 42 and 43 beds) included patients in general internal medicine, gastroenterology, oncology, nephrology and haematology.

During the period between May to December 2005 (32 weeks) one senior clinical pharmacist (ML) conducted 70 observation days taking part in clinical ward rounds and reviewing daily all the non-formulary prescriptions and the case notes of one of five nursing subunits of the ward (representing 10-15 patients). All clinical pharmaceutical interventions were classified as DRPs according to the PCNE System V5.00 and then entered into an Excel spread sheet (Microsoft Corp., Redmond, Oregon) including the drugs involved.

\section{Acceptance of pharmacists' interventions}

In the PCNE classification the items $11.3-11.5$ were all considered suitable for a modification in therapy. Interventions at prescriber level proposing an approved change in drug therapy, were classified at drug level in order to get more detailed information. 
The acceptance rate was calculated as the sum of interventions with PCNE codes 11.3 and 13.x divided by the sum of all interventions proposing modifications (PCNE codes 11.3, 11.4, 11.5, and 13.x).

\section{Cost avoidance}

The cost avoidance of interventions directly linked to a reduction in medication usage was calculated. These interventions were: switching from i.v. to p.o. of the same drug (represented by PCNE code P2.2 [Inappropriate drug form] in combination with $\mathrm{C} 1.3$ [More cost-effective drug available]), dose reductions (P3.2 [Drug dose too high] in combination with 13.2 [Dosage changed]) and stopping unnecessary medications (13.5 [Drug stopped]). For the calculation we presumed that inappropriate drug therapies would have continued for three days without being detected. As an assumption, we counted reduction of dosage as half price. Drug costs were calculated on the basis of defined daily doses and official prices given in the Swiss Drug Formulary [13]. In order to get a yearly estimate, all the directly cost-linked interventions during the 70 observation days were added up to a year of 365 working days.

\section{Results}

Classification of drug-related problems

In the observation period, 1, 444 patients were discharged from the two wards representing 17,476 patient days. There were 0.15 interventions per patient counting up to 1.22 interventions per 100 patient days.

A total of 213 pharmaceutical interventions were recorded, whereof $33(15.5 \%)$ were initiated on ward rounds, $128(60.1 \%)$ on case note review, $32(15.0 \%)$ as a consequence of specific requests and 20 (9.4\%) interventions by non-formulary drug orders. To each intervention a cause and a problem code could be attributed except six cases $(2.8 \%)$ without a suitable problem category. The nonclassified problems are listed in Table 1.

\section{Problems}

The major DRPs identified were related to incorrect drug choice (PCNE-Code P2) in 38\% $(n=81) ; 24 \%(n=52)$ were drug dosage problems (P3), followed by drug-drug or drug-food interactions (P5) in $17 \%(n=37)$. ADRs (P1) accounted for $10 \%(n=22)$ of the problems. The detailed analysis of the 207 DRPs are shown in Table 2: potential drug interactions $(16.4 \%, n=34$; P5.1) are most frequent, followed by overdose $(14.5 \%, n=30$; P3.2) and inappropriate choice of drug form $(12.6 \%, n=26, \mathrm{P} 2.2), 20$ (9.7\%) problems regarding too low a dose (P3.1), 15 (7.2\%) observations with no clear indication for drug use (P2.5) and 14 (6.8\%) non-allergic ADRs (P1.1).

\section{Causes}

The overview of the causes $(n=213)$ shows a majority $(68 \%, n=145)$ that was related to the selection of the drug and/or dosage schedule (C1). The second most common cause with $15 \%(n=33)$ involved the drug use process (C2), i.e., administration and timing of drugs. Patient factors (C4) seemed to play a minor role $(1 \%, n=2)$. Aspects concerning information about the treatment (C3), logistics (C5), e.g., availability of drugs, and other causes (C6) were noted each in 11 cases $(5 \%)$.

The detailed analysis of the causes (Table 3) shows that pharmacokinetics due to organ dysfunction and interactions (C1.4) played a major role (19\%) followed by inappropriate timing of administration and dosing intervals $(\mathrm{C} 2.1 ; 11 \%, n=24)$ and inappropriate drug selection (C1.1; 10\%, $n=22)$.

\section{Inverventions}

All of the causes led to an intervention $(n=213)$. Most of them took place at the drug level $(13 ; 54 \%, n=116)$, followed by interventions at the prescriber level e.g. explaining a drug-drug interaction $(11 ; 32 \%, n=69)$. The rest of interventions were at the patient/carer level (12) or "other activity" (14), each resulting in 7\% $(n=14)$ of interventions (Table 4).

Table 1 Problems which could not be classified by the PCNE-System

\begin{tabular}{lllll}
\hline No. & Cause & Intervention & Drug & Description of problems \\
\hline 1 & C2.1 & 13.4 & Tamsulosin & Drug should be taken before the meals \\
2 & C2.1 & 13.4 & Isoniazid/Pyrazinamid/Rifampin & Drug should be taken before the meals \\
3 & C2.1 & 13.4 & Lipase/Amylase/Protease & $\begin{array}{l}\text { Drug should be taken before the meals } \\
\text { Drug should not be administered parallel to a certain } \\
\text { other drug (incompatibility problem) }\end{array}$ \\
4 & C2.1 & 13.4 & Piperacillin/Tazobactam & Topical cytostatic drug, special instructions for use must be followed \\
5 & C3.1 & 12.2 & Fluorouracil & Obvious prescribing error (no more details available) \\
\hline
\end{tabular}


Table 2 Detected drug-related problems $(n=207)$, classified according to PCNE-Classification V5.0 [11]

\begin{tabular}{|c|c|c|c|c|}
\hline Primary domain & Code & Detailed classification & $n$ & $\%$ \\
\hline 1. Adverse reactions & P1 & Total & 22 & 10 \\
\hline \multirow[t]{3}{*}{ Patient suffers from an adverse drug event } & P1.1 & Side effect suffered (non-allergic) & 14 & 6.8 \\
\hline & P1.2 & Side effect suffered (allergic) & 5 & 2.4 \\
\hline & P1.3 & Toxic effects suffered & 3 & 1.4 \\
\hline 2. Drug choice problem & P2 & Total & 81 & 38 \\
\hline \multirow{6}{*}{$\begin{array}{l}\text { Patient gets or is going to get a wrong (or no } \\
\text { drug) drug for his/her disease } \\
\text { and/or condition }\end{array}$} & $\mathrm{P} 2.1$ & Inappropriate drug (not most & 11 & 5.3 \\
\hline & $\mathrm{P} 2.2$ & Inappropriate drug form (not most appropriate for indication) & 26 & 12.6 \\
\hline & $\mathrm{P} 2.3$ & Inappropriate duplication of therapeutic group or active ingredient & 7 & 3.4 \\
\hline & P2.4 & Contra-indication for drug (incl. Pregnancy/breast feeding) & 12 & 5.8 \\
\hline & $\mathrm{P} 2.5$ & No clear indication for drug use & 15 & 7.2 \\
\hline & $\mathrm{P} 2.6$ & No drug prescribed but clear indication & 10 & 4.8 \\
\hline 3. Dosing problem & P3 & Total & 52 & 24 \\
\hline \multirow{4}{*}{$\begin{array}{l}\text { Patient gets more or less than the } \\
\text { amount of drug he/she requires }\end{array}$} & P3.1 & Drug dose too low or dosage & 20 & 9.7 \\
\hline & P3.2 & Drug dose too high or dosage regime too frequent & 30 & 14.5 \\
\hline & P3.3 & Duration of treatment too short & 0 & 0.0 \\
\hline & P3.4 & Duration of treatment too long & 2 & 1.0 \\
\hline 4. Drug use problem & $\mathrm{P} 4$ & Total & 7 & 3.4 \\
\hline \multirow[t]{2}{*}{ Wrong or no drug taken/administered } & P4.1 & Drug not taken/administered at all & 6 & 2.9 \\
\hline & $\mathrm{P} 4.2$ & Wrong drug taken/administered & 1 & 0.5 \\
\hline 5. Interactions & P5 & Total & 37 & 17 \\
\hline \multirow{2}{*}{$\begin{array}{l}\text { There is a manifest or potential drug-drug } \\
\text { or drug-food interaction }\end{array}$} & P5.1 & Potential interaction & 34 & 16.4 \\
\hline & P5.2 & Manifest interaction & 3 & 1.4 \\
\hline \multirow[t]{5}{*}{ 6. Others } & P6 & Total & 8 & 3.9 \\
\hline & P6.1 & Patient dissatisfied with therapy despite taking drug(s) correctly & 4 & 1.9 \\
\hline & P6.2 & $\begin{array}{l}\text { Insufficient awareness of health and diseases (possibly leading to future } \\
\text { problems) }\end{array}$ & 2 & 1.0 \\
\hline & P6.3 & Unclear complaints. Further clarification necessary & 1 & 0.5 \\
\hline & P6.4 & Therapy failure (reason unknown) & 1 & 0.5 \\
\hline
\end{tabular}

\section{Acceptance indicator}

In the PCNE classification the items 11.3 to 11.5 and all the interventions at drug level (13.x) can be considered as propositions for a modification in therapy (changes in drug prescription or other non-pharmacological measures such as the monitoring of drug levels or other laboratory parameters) subjected to physician's approval. In our sample 148 interventions of 213 concerned therapy modifications $(69 \%)$. $83 \%$ were adopted by physicians (PCNE Codes 11.3/13.x, $6 \%$ were rejected (11.4), and in 16 cases (11\%) the outcome remained unknown (11.5) (Fig. 2).

The remaining 65 interventions are not subject to physician approval. Almost half of these $(47.7 \%, n=31)$ involved giving more information to the prescriber, typically about potential drug-drug interactions requiring closer clinical patient monitoring. Another twelve interventions were ADRs reported to the pharmacovigilance centre.

Cost avoidance

A total of 51 interventions (24\%) were considered to be directly related to a cost saving without affecting quality of care (Table 5).

Of these 51 cost-relevant interventions 22 (43.1\%) accounted for stopping of medication, which was no longer required, $16(31.4 \%)$ for switching from i.v. to p.o. medications and $13(25.5 \%)$ for dosage adjustments.

The interventions stopping unnecessary drugs showed a mean saving of $€ 10.11$ resulting in $€ 1,158$ for the period of one year (365 working days). Interventions which switched 
Table 3 Causes for drug-related problems $(n=213)$, classified according to PCNE-Classification V05 [11]

\begin{tabular}{|c|c|c|c|c|}
\hline Primary domain & Code & Detailed classifcation & $N$ & $\%$ \\
\hline 1. Drug/dose selection & $\mathrm{C} 1$ & Total & 145 & 68 \\
\hline \multirow{8}{*}{$\begin{array}{l}\text { The cause of the DRP is related to the selection } \\
\text { of the drug and/or dosage schedule }\end{array}$} & $\mathrm{C} 1.1$ & Inappropriate drug selection & 22 & 10.3 \\
\hline & $\mathrm{C} 1.2$ & Inappropriate dosage selection & 15 & 7.0 \\
\hline & $\mathrm{C} 1.3$ & More cost-effective drug available & 18 & 8.5 \\
\hline & $\mathrm{C} 1.4$ & $\begin{array}{l}\text { Pharmacokinetic problems, incl. ageing/ deterioration } \\
\text { in organ function and interactions }\end{array}$ & 41 & 19.2 \\
\hline & $\mathrm{C} 1.5$ & Synergistic/preventive drug required and not given & 6 & 2.8 \\
\hline & C1.6 & Deterioration/improvement of disease state & 17 & 8.0 \\
\hline & $\mathrm{C} 1.7$ & New symptom or indication revealed/presented & 12 & 5.6 \\
\hline & $\mathrm{C} 1.8$ & Manifest side effect, no other cause & 14 & 6.6 \\
\hline 2. Drug use process & $\mathrm{C} 2$ & Total & 33 & 15 \\
\hline \multirow{6}{*}{$\begin{array}{l}\text { The cause of the DRP can be related to the } \\
\text { way the patient uses the drug, in spite of } \\
\text { proper dosage instructions (on the label) }\end{array}$} & $\mathrm{C} 2.1$ & $\begin{array}{l}\text { Inappropriate timing of administration and/or dosing } \\
\text { intervals }\end{array}$ & 24 & 11.3 \\
\hline & $\mathrm{C} 2.2$ & Drug underused/under-administered & 2 & 0.9 \\
\hline & $\mathrm{C} 2.3$ & Drug overused/over-administered & 1 & 0.5 \\
\hline & $\mathrm{C} 2.4$ & Therapeutic drug monitoring required & 1 & 0.5 \\
\hline & $\mathrm{C} 2.5$ & Drug abused (unregulated overuse) & 1 & 0.5 \\
\hline & $\mathrm{C} 2.6$ & Patient unable to use drug/form as directed & 4 & 1.9 \\
\hline 3. Information & $\mathrm{C} 3$ & Total & 11 & 5.2 \\
\hline \multirow{5}{*}{$\begin{array}{l}\text { The cause of the DRP can be related to a } \\
\text { lack or misinter pretation of information }\end{array}$} & $\mathrm{C} 3.1$ & Instructions for use/taking not known & 6 & 2.8 \\
\hline & $\mathrm{C} 3.2$ & Patient unaware of reason for drug treatment & 0 & 0.0 \\
\hline & $\mathrm{C} 3.3$ & $\begin{array}{l}\text { Patient has difficulties reading/understanding patient } \\
\text { information form/leaflet }\end{array}$ & 1 & 0.5 \\
\hline & $\mathrm{C} 3.4$ & Patient unable to understand local language & 0 & 0.0 \\
\hline & $\mathrm{C} 3.5$ & $\begin{array}{l}\text { Lack of communication between healthcare } \\
\text { professionals }\end{array}$ & 4 & 1.9 \\
\hline 4. Patient/psychological & $\mathrm{C} 4$ & Total & 2 & 1 \\
\hline \multirow{10}{*}{$\begin{array}{l}\text { The cause of the DRP can be related to the } \\
\text { personality or behaviour of the patient }\end{array}$} & $\mathrm{C} 4.1$ & Patient forgets to use/take drug & 0 & 0.0 \\
\hline & $\mathrm{C} 4.2$ & Patient has concerns with drugs & 0 & 0.0 \\
\hline & $\mathrm{C} 4.3$ & Patent suspects side-effect & 0 & 0.0 \\
\hline & $\mathrm{C} 4.4$ & Patient unwilling to carry financial costs & 0 & 0.0 \\
\hline & $\mathrm{C} 4.5$ & Patient unwilling to bother physician & 0 & 0.0 \\
\hline & C4.6 & Patient unwilling to change drugs & 0 & 0.0 \\
\hline & $\mathrm{C} 4.7$ & Patient unwilling to adapt life-style & 0 & 0.0 \\
\hline & $\mathrm{C} 4.8$ & Burden of therapy & 1 & 0.5 \\
\hline & C4.9 & Treatment not in line with health beliefs & 0 & 0.0 \\
\hline & $\mathrm{C} 4.10$ & Patient takes food that interacts with drugs & 1 & 0.5 \\
\hline 5. Logistics & C5 & Total & 11 & 5.2 \\
\hline \multirow{3}{*}{$\begin{array}{l}\text { The cause of the DRP can be related to the logistics of the } \\
\text { prescribing or dispensing mechanism }\end{array}$} & C5.1 & Prescribed drug not available & 6 & 2.8 \\
\hline & C5.2 & Prescribing error (only in case of slip of the pen) & 4 & 1.9 \\
\hline & C5.3 & Dispensing error (wrong drug or dose dispensed) & 1 & 0.5 \\
\hline \multirow[t]{3}{*}{ 6. Others } & C6 & Total & 11 & 5.2 \\
\hline & C6.1 & Other cause; specify & 1 & 0.5 \\
\hline & C6.2 & No obvious cause & 10 & 4.7 \\
\hline
\end{tabular}

an i.v. drug to p.o. $(n=13)$ resulted in a mean cost saving of $€ 93.30$ per intervention, i.e., $€ 7,785$ annually. Assuming that dose reductions equate to half the price of the daily regular dose of a drug for three treatment days, dose adjustments for the 13 interventions led to a cost reduction of $€ 343$ for all and $€ 26.35$ per single dose adjustment. Over 
Table 4 Pharmacist's interventions for drug-related problems $(n=213)$, classified according to PCNEClassification V05 [11]

\begin{tabular}{|c|c|c|c|c|}
\hline Primary domain & Code & Intervention & $n$ & $\%$ \\
\hline No intervention & I0.0 & No intervention & 0 & 0.0 \\
\hline \multirow[t]{6}{*}{ 1. At prescriber level } & 11 & Total & 69 & 32 \\
\hline & 11.1 & Prescriber informed only & 31 & 14.6 \\
\hline & 11.2 & Prescriber asked for information & 6 & 2.8 \\
\hline & 11.3 & Intervention proposed, approved by Prescriber & 7 & 3.3 \\
\hline & 11.4 & Intervention proposed, not approved by Prescriber & 9 & 4.2 \\
\hline & 11.5 & Intervention proposed, outcome unknown & 16 & 7.5 \\
\hline \multirow[t]{5}{*}{ 2. At patient/carer level } & 12 & Total & 14 & 6.6 \\
\hline & 12.1 & Patient (medication) counselling & 4 & 1.9 \\
\hline & 12.2 & Written information provided only & 10 & 4.7 \\
\hline & 12.3 & Patient referred to prescriber & 0 & 0.0 \\
\hline & 12.4 & Spoken to family member/caregiver & 0 & 0.0 \\
\hline \multirow[t]{7}{*}{ 3. At drug level } & 13 & Total & 116 & 54 \\
\hline & 13.1 & Drug changed & 22 & 10.3 \\
\hline & 13.2 & Dosage changed & 28 & 13.1 \\
\hline & 13.3 & Formulation changed & 10 & 4.7 \\
\hline & 13.4 & Instructions for use changed & 27 & 12.7 \\
\hline & 13.5 & Drug stopped & 22 & 10.3 \\
\hline & 13.6 & New drug started & 7 & 3.3 \\
\hline \multirow[t]{3}{*}{ 4. Other intervention or activity } & 14 & Total & 14 & 6.5 \\
\hline & 14.1 & Other intervention (specify) & 2 & 0.9 \\
\hline & 14.2 & Side effect reported to authorities & 12 & 5.6 \\
\hline
\end{tabular}

documentation system. In their proposed intervention section it contains items often used like "administration mode optimisation" or "change of administration route", and in the problems section "improper administration" [10]. A major draw-back of their system is that neither a description of the cause nor options for the documentation of interventions at the patient level are provided. Combining the PCNE system with these elements would create a welladapted tool. Future work should additionally address the assessment of DRP severity and the clinical impact of the pharmacist's intervention as proposed in literature [14-16].

Time is a key aspect for the acceptance of a documentation system. Practicability of the PCNE system in daily routine proved to be easy to use and barely time-consuming. The daily documentation classifying the DRP and entering the PCNE codes and the drugs into the database (Excel spreadsheet) took only a few minutes. Ganso using the PI-Doc system on a Microsoft Access database measured on average $1.9 \mathrm{~min}$ for the classification and $6.5 \mathrm{~min}$ for the electronic documentation/intervention [17].

The documentation of DRPs with the PCNE system in everyday practice seems to provide realistic and comparable data about the impact of clinical pharmacy services on drug treatment. The acceptance of the pharmacist's interventions was $83 \%$, a figure well in accordance with 
Fig. 2 Types of pharmaceutical interventions and their acceptance by the prescribers

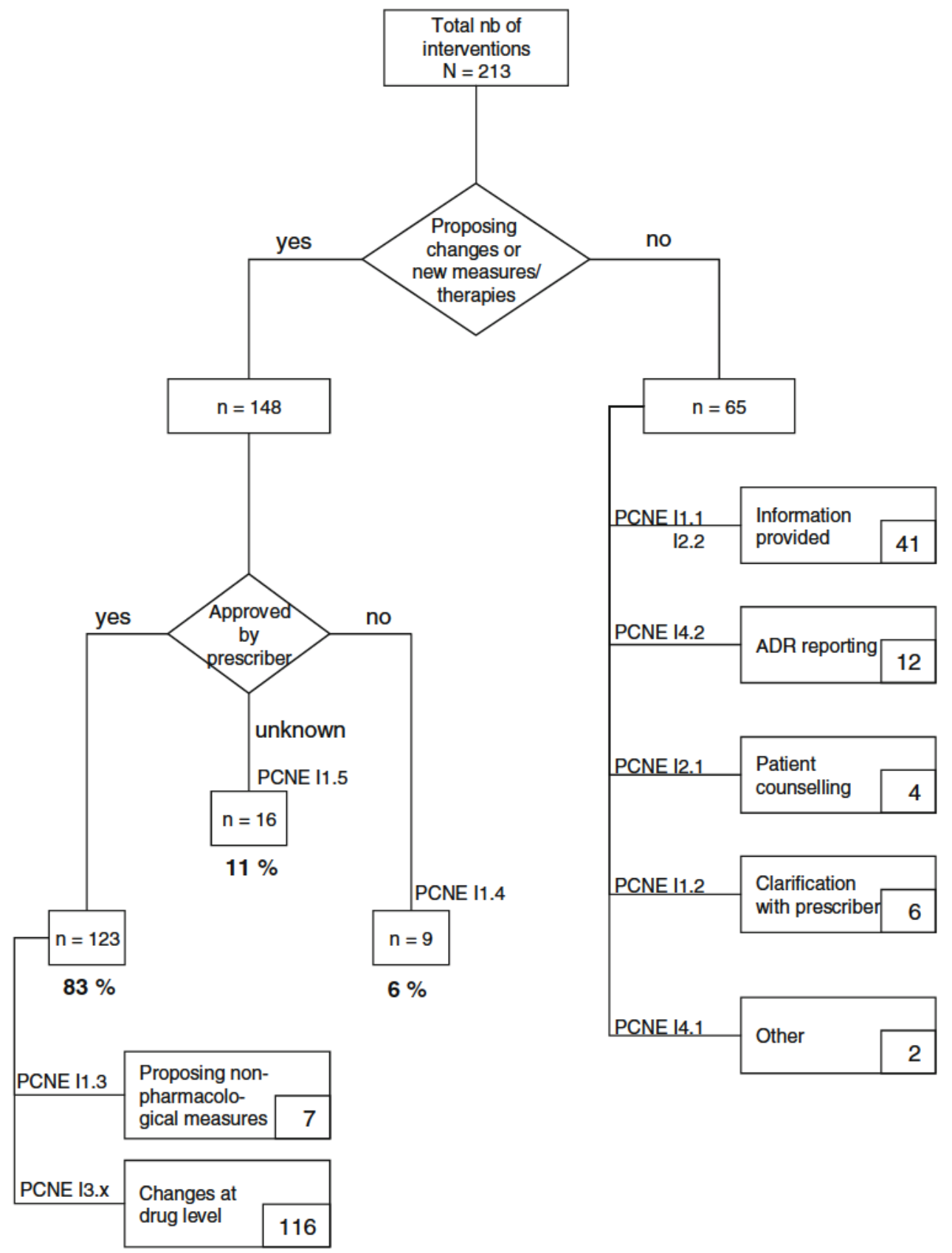

Table 5 Cost avoidance by clinical pharmaceutical interventions

\begin{tabular}{lllcr}
\hline & PCNE Code & No. of observations & Avoided costs $(\epsilon)$ & One year estimate $(365$ days; $\epsilon)$ \\
\hline Stopping unnecessary drugs & 13.5 & $22(43.1 \%)$ & $222^{\mathrm{a}}$ & 1,158 \\
Switching from i.v. to p.o. & {$[\mathrm{P} 2.2+\mathrm{C} 1.3]$} & $16(31.4 \%)$ & $1,493^{\mathrm{b}}$ & 7,785 \\
Dose adjustments & {$[\mathrm{P} 3.2+13.2]$} & $13(25.5 \%)$ & $343^{\mathrm{c}}$ & 1,788 \\
Total & & $51(100 \%)$ & 2058 & 10,731 \\
\hline
\end{tabular}

${ }^{a}$ Assuming continued application of this drug for another 3 days

b Assuming continuation of 3 days i.v. therapy

c 3 days' treatment at $50 \%$ price 
other studies. A review of 23 studies found an average acceptance rate of $85.5 \%$ [18]. Some studies, however, may show acceptance rates of up to $99 \%$, but the provision of drug information was also counted as an intervention, whereas in our calculation this item (PCNE 11.1: Prescriber informed only) was not included [19].

Clinical pharmacy service can reduce drug costs. Our study of a single CP's activity showed a cost avoidance of over 10,000 $€$ /year. Twenty-five percent of interventions had direct influence on drug costs, a similar rate to the study of McMullin with 26\% [20]. A recent study from Denmark assessed the cost effects of a clinical pharmacist in a controlled prospective study [21]. Cost reductions resulted in $43 \%$ of the interventions with total savings of direct drug costs of $3442 €$ within one year. The difference to our findings showing cost savings up to more than $10,000 € /$ year can be explained by methodological differences. Our results base on assumptions for calculation. Minor changes in the assumptions would lead to different results. Second, we extrapolate from our study period of 70 observation days in a period of 8 months to a whole year of 365 working days. In such a design random effects may occur (one single case with extraordinary high costs or cost savings) which are then extrapolated to one year.

But in spite of these restrictions, our findings do not seem unrealistic in comparison to other studies. Ganso found cost reductions ranging from 17 to $27 € /$ intervention on average in four different wards ( 3 surgery wards, 1 endocrinology ward) [17] whereas we calculated $34 \mathrm{E} /$ intervention. In particular the cost savings of switching from i.v. to p.o. application is well within the range of former results. Our study confirms Ruettimann's cost savings of $93 €$ per switch of antibiotics [22]. Our estimations still are conservative taken into account we assumed work during daytime only.

Our study has several limitations. A major limitation is the possible bias in the detection and classification of DRPs since all the pharmaceutical interventions derive from a single site, a single medical floor and only one person identified, resolved and classified the DRPs. Using a crossover design with two pharmacists and kappa statistics would substantially reduce this bias. Local staffing restrictions unfortunately did not allow us to follow such a design. Furthermore, results from wards of other medical specialties should be compared to the medical wards in our study. Third, we show cost avoidance by the CP's interventions. The use of billing data, outcome measures and adjustment for age, gender and casemix, would enable real costs to be computed.

\section{Conclusion}

In conclusion, we consider the PCNE system with the four levels of classification a very useful and easy-to-use tool for the documentation of clinical pharmacy services not only for research purposes but also in daily hospital practice. Data generated by such a documentation system are increasingly important to provide information on the impact of the clinical pharmaceutical services supplied and identification of staff needs [23].

Acknowledgements We would like to thank Monika Gisin, RN and Kristian Schneider, RN for their support and interest in setting up a clinical pharmacy service. We would also like to thank Peter Hockey, MD for his critical review of the text.

Funding There was no financial support for his study.

Conflicts of interest There was no conflict of interest.

\section{References}

1. Krähenbühl-Melcher A, Schlienger R, Lampert M, Haschke M, Drewe J, Krähenbühl S. Drug related problems in hospitals-a review of the recent literature. Drug Saf. 2007;30:379-407.

2. Schlienger RG, Luescher TF, Schoenenberger RA, Haefeli WE. Academic detailing improves identification and reporting of adverse drug events. Pharm World Sci. 1999;3:110-5.

3. Forster AJ, Murff HJ, Peterson JF, Gandhi TK, Bates DW. The incidence and severity of adverse events affecting patients after discharge from the hospital. Ann Intern Med. 2003;138:161-7.

4. Kaboli PJ, Hoth AB, McClimon BJ, Schnipper JL. Clinical pharmacists and inpatient medical care-a systematic review. Arch Intern Med. 2006;166:955-64.

5. Schumock GT, Butler MG, Meek PD, Vermeulen LC, Arondekar BV, Bauman JL. 2002 Task force on economic evaluation of clinical pharmacy services of the American College of Clinical Pharmacy. Pharmacotherapy. 2003;23:113-32.

6. Ferner RE, Aronson JK. Clarification of terminology in medication errors. Drug Saf. 2006;29:1011-22.

7. Pharmaceutical Care Network Europe. PCNE Classification for Drug-related Problems V5.00. 2005. www.pcne.org/dokumenter/ PCNE\%20classificationV5.00.pdf (download 02-05-2005).

8. Aronson JK. A prescription for better prescribing. Br J Clin Pharmacol. 2006;61:487-91.

9. Van Mil F, Westerlund T, Hersberger KE, Schaefer MA. Drugrelated problem classification systems. Ann Pharmacother. 2004;38:859-67.

10. Allenet B, Bedouch P, Rose FX, et al. Validation of an instrument for the documentation of clinical pharmacists' interventions. Pharm World Sci. 2006;28:181-8.

11. AbuRuz SM, Bulatova NR, Yousef AM. Validation of a comprehensive classification tool for treatment related problems. Pharm Word Sci. 2006;28:222-32.

12. Schaefer M. Discussing basic principles for a coding system of drug-related problems: the case of PI-Doc. Pharm World Sci. 2002;24:120-7.

13. Lagler M, editor. Arzneimittelkompendium der Schweiz. 2007. 28th ed. (ISBN 3-85640-313-2), Basel: Documed; 2006.

14. Hatoum HT, Hutchinson RA, Elliott LR, Kendzierski DL. Physicians' review of significant interventions by clinical pharmacists in inpatient care. Drug Intell Clin Pharm. 1988;22:980-2.

15. Dooley MJ, Allen KM, Doecke CJ, et al. A prospective multicentre study of pharmacist initiated changes to drug therapy and patient management in acute care government funded hospitals. Br J Clin Pharm. 2004;57:513-21. 
16. Overhage JM, Lukes A. Practical, reliable, comprehensive method for characterizing pharmacists' clinical activities. Am J Health Syst Pharm. 1999;56:2444-50.

17. Ganso M. Documentation and analysis of pharmaceutical interventions, 6. Konstanzer Apothekerkolloquium. 2006. (Oral Communication).

18. Klopfer JD, Einarson TR. Acceptance of pharmacists' suggestions by prescribers: a literature review. Hosp Pharm. 1990; 25:830-6.

19. Leape LL, Cullen DJ, Clapp MD et al. Pharmacist participation on physician rounds and adverse drug events in the intensive care unit. JAMA. 1999;282:267-70.

20. McMullin ST, Hennenfelt JA, Bailey TC, et al. A prospective, randomized trial to assess the cost of pharmacist-initiated interventions. Arch Int Med. 1999;159:2306-9.
21. Croft Buck T, Brandstru L, Brandslund I, Kampmann JP. The effects of introducing a clinical pharmacist on orthopaedic wards in Denmark. Pharm World Sci. 2007;29:12-8.

22. Ruettimann S, Keck B, Hartmeier C, Maetzel A, Bucher HC. Long-term antibiotic cost savings from a comprehensive intervention program in a medical department of a universityaffiliated teaching hospital. Clin Infect Dis. 2004;38:348-56.

23. Bajcar J, Chin T, Chui W, Wichman K. Development of a comprehensive clinical pharmacy workload documentation system. Can J Hosp Pharm. 1995;48:80-9. 